\title{
Early Evaluation of Impacts of Cold Waves and Floods During Winter 2018 in France
}

Anne Fouillet, Cécile Forgeot, Marie-Michèle Thiam, Céline Caserio-Schönemann

Division of Data Science, Santé publique France, Saint-Maurice, France

Objective

The presentation describes the results of the daily monitoring of health indicators conducted by the French public health age ncy during the major floods and the cold wave that occurred in January 2018 in France, in order to early identify potential impact of those climatic events on the population.

\section{Introduction}

The Seine River rises at the north-East of France and flows through Paris before emptying into the English Channel. On January 2018 (from 22th January to 11th February, Weeks 4 to 6), major floods occurred in the Basin of Seine River, after an important rainy period. This period was also marked by the occurrence on the same area of a first cold wave on Week 6 (from $5^{\text {th }}$ to $7^{\text {th }}$ February), including heavy snowfall and ice conditions from $9^{\text {th }}$ to $10^{\text {th }}$ February. A second similar cold wave occured from $28^{\text {th }}$ February and $1^{\text {st }}$ March.

Floods of all magnitude are known to have potential health impacts on population [1], both at short, medium and long term both on physical (injuries, diarrhoeal disease, Carbon Monoxyde poisoning, vector-borne disease) and mental health. Extreme cold weather have also the potential to further impact on human health through direct exposure to lower temperatures, and associated adverse conditions, such as snow and ice [2]. Such situations may be particularly associated to direct impact like hypothermia, frostbite and selected bone/joint injuries).

\section{Methods}

Since 2004, the French Public Health Agency (Santé publique France) set up a national syndromic surveillance system SurSaUD, enabling to ensure morbidity and mortality surveillance [3]. In 2018, morbidity data were daily collected from a network involving about 700 emergency departments (ED) and 58 emergency general practitioners' associations SOS Médecins. 92\% of the national ED attendances and $95 \%$ of national SOS Médecins visits are caught by the system.

Both demographic (age and gender), administrative (date and location of consultation, transport) and medical information (chief complaint, medical diagnosis using ICD10 codes in ED and specific thesauri in SOS Médecins associations, severity, hospitalization after discharge) are recorded for each patient.

The daily and weekly evolution of the number of all-cause ED attendances and SOS Médecins consultations during the flooding period were compared to the evolution on the two previous years. The number of hospitalisations after ED discharge was also monitored. The immediate health impact of floods and cold waves was assessed by monitoring eight syndromic indicators: gastroenteritis, carbon monoxide poisoning, burnt, stress, faintness, drowning, injuries and hypothermia. Analyses were performed by age group ( $<15$ years, 15-64 years, more than 65 years) and at different geographical levels (national, Paris region and districts located in the Basin of Seine River).

\section{Results}

In 2018, syndromic surveillance did not show any major impact on all-cause ED attendances and SOS Médecins consultations from week 4 to week 6, neither in Paris area nor in other areas along the Seine River. The recorded numbers were comparable to the two precedent years in all age groups.

ISDS Annual Conference Proceedings 2019. This is an Open Access article distributed under the terms of the Creative Commons AttributionNoncommercial 4.0 Unported License (http://creativecommons.org/licenses/by-nc/3.0/), permitting all non-commercial use, distribution, and reproduction in any medium, provided the original work is properly cited. 
A decrease of the all-cause ED attendances was observed during the 1st day with ice conditions in Normandy and Paris, mainly in children and adults aged 15-64 years.

During week 6 in Paris area, an increase of ED attendances was observed for injuries (+4\% compared to the past weeks - figure 1) and to a lesser extent for hypothermia and frostbite (16 attendances compared to less than 9 for the past weeks). Similar increase in injuries were observed in Normandy during the second cold wave (Figure 1).

\section{Conclusions}

During the flood episode, the rising water level was slow with foreseeable evolution, compared to other sudden flood events occurring in south of France in 2010 due to violent thunderstorms. This progressive evolution allows French authority to deploy wide specific organization in order to mitigate impact on concerned populations. That may explain the absence impact observed in ED at regional and national levels during the flood disaster. The evolution of injuries during 2018 episode is attributable to the cold wave that occurred simultaneously.

As the French syndromic surveillance system is implemented on the whole territory and collects emergency data routinely since several years, it constitutes a reactive tool to assess the potential public health impact of both sudden and predictable dis asters. It can either contribute to adapt management action or reassure decision makers if no major impact is observed.

\section{Acknowledgement}

To all emergency departments of the OSCOUR network, SOS Médecins associations and to the regional teams in charge of syndromic surveillance.

\section{References}

1. Ahern M, Kovats S. The health impacts of floods. In: Few R, Matthies F, eds. Flood hazards and health: responding to present and future risks. London, Earthscan, 2006:28-53.

2. Hughes HE, Morbey R, Hughes T, et al. 2014. Using an Emergency Department Syndromic Surveillance System to investigate the impact of extreme cold weather events. Public Health. 128(7), 628-35. PubMed https://doi.org/10.1016/j.puhe.2014.05.007

3. Caserio-Schönemann C, Bousquet V, Fouillet A, Henry V. 2014. The French syndromic surveillance system SurSaUD (R). Bull Epidemiol Hebd (Paris). 3-4, 38-44.

Figure 1: daily proportion of ED attendances for injuries among the whole attendances in Paris area and Normandy in adults aged 15-64 years - From November to March 2015-2018 - Flood period in blue zone
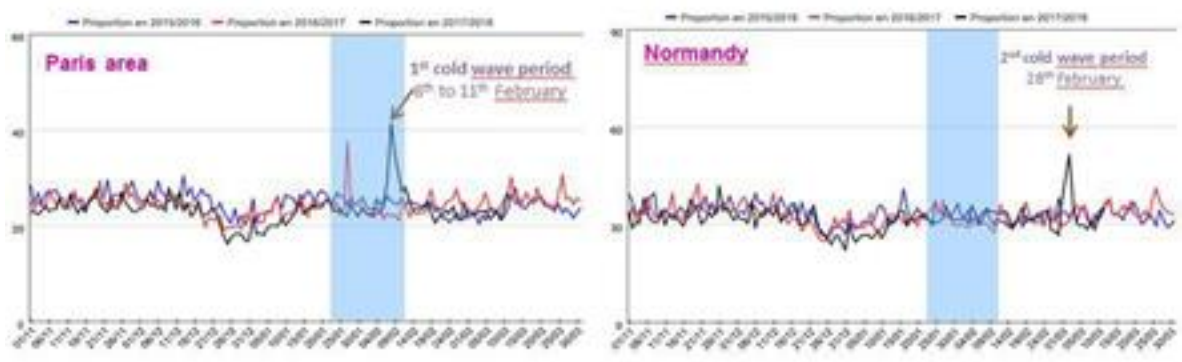

ISDS Annual Conference Proceedings 2019. This is an Open Access article distributed under the terms of the Creative Commons AttributionNoncommercial 4.0 Unported License (http://creativecommons.org/licenses/by-nc/3.0/), permitting all non-commercial use, distribution, and reproduction in any medium, provided the original work is properly cited. 